\title{
An improved version of Leasys: an intelligent plant identification system
}

\author{
Abdul Rahaman, Abdulllahi Alanamu ${ }^{1}$, Asaju, La'aro Bolaji ${ }^{2 *}$, Arigbede, Moses Olasupo ${ }^{3}$, Oladele, \\ Felix Ayotunde ${ }^{4}$
}

\section{N F O}

Received 9 Dec. 2011

Accepted 16 May. 2012

Available on-line 15 Jun. 2012

Responsible Editor: K. Rajkai

\section{Keywords:}

Computer system, herbarium,

Leasys system version 1.1,

plant identification, savanna tree species

\begin{abstract}
A B S T R A C T
In an attempt to make identification of plants easy and less cumbersome, computer-based software called Leasys was developed. It is a computerized version of a field key prepared for on-the-spot identification of savanna tree species in Nigeria. Leasys 1.1 is an improved version of the earlier version developed by the same authors. The current version is more expansive than the first version and thus has more features which make identification process faster and easier. Incorporated in Leasys 1.1 are some other features that make it more robust, flexible and versatile. These features include Leasys Property Registration which makes identification of a plant along two selection paths possible, Leasys Plant Management which inserts, updates and deletes plant data from the database, Leasys Deduction System whicht enables the user identify a plant by inputting a leaf feature and Leasys Quick Search which brings about fast identification of plant without going through the step by step process of identification. It is also possible to print one or all results generated. Leasys has a database on two hundred (200) different savanna trees. The system has the potential and capacity to accommodate very large number of species and very large number of taxonomic characters. With the implementation of a specialized algorithm based on the SQL OLEDB engine, AND operator professional reporting system, impressive nature GUI's network compatibility and an enhanced interaction level, Leasys has the great potengtial for progressive upgrading.
\end{abstract}

\section{Introduction}

Usefulness of plants to humanity cannot be over emphasized. Plants are used for a vast number of items which directly or indirectly affect human life positively. Scientists as well as other professionals made use of plants and thus research is endless on how to further harness more potentials in plants that are yet to be recognized. It is therefore imperative to find ways of making plant identification easier and efficient. In the words of Ramesh and Ayyappan (2009) there is growing scientific consensus that habitats are altered and species are disappearing at rates never before witnessed on the planet earth. The biodiversity crisis is not just about the perilous state of plants and animals but also endangering of specialists who know them. Meanwhile, for accurate and reliable research results on plants there is therefore need for accurate and easy identification process system of plants. Plant identification process involves comparisons of certain characteristics and then assigning a particular identity to an unknown plant, using tools called taxonomic keys e.g. dichotomous key (indented and bracketed). The process of going through the contrasting statements or leads in these keys can be laborious and timeconsuming. Hence several attempts have been made to make plant identification easier (Hopkins and Stanfield, 1966; Doyle and Becker, 1975; Singhal, 2001; Cope, 2001; Belhumeur et al., 2008; Zhang

\footnotetext{
${ }^{1}$ AbdulRahaman, Abdulllahi. Alanamu

Department of Plant Biology, University of Ilorin, Ilorin, Nigeria. abdulrahamanaa@unilorin.edu.ng

2* Asaju, La'aro Bolaji

Corresponding Author

Department of Computer Science, University of Ilorin, Ilorin, Nigeria .

lbasaju@gmail.com

3 Arigbede Moses Olasupo

Department of Computer Science, University of Ilorin, Ilorin, Nigeria

softdir@yahoo.com

4 Oladele, Felix Ayotunde

Department of Plant Biology, University of Ilorin, Ilorin, Nigeria.

oladele.fa@unilorin.edu.ng
} 
et al. 2008; Breen, 2009). Even though, there are many manual keys such as the above ones which aid in identification of unknown plants, botanists and computer experts are now combining ideas in finding solutions to the time-consuming and cumbersomeness of the taxonomic keys (Zheng et al., 2008; Hossain and Amin, 2010; Rashad et al., 2011). In most of the computer-based systems, some plant parts such as leaves, flowers and plant habits are used for identification of plants species. AbdulRahaman et al. (2010) chose the field key to 200 savanna tree species in Nigeria, published by Hopkins and Stanfield (1966), with key entry points being based on simple and compound leaves. It is a simple field key, which AbdulRahaman et al (2010) computerized to give Leasys. This system was found to have some shortcomings, hence the need for present study to improve on it. Leasys 1.1 is the modification of Leasys of AbdulRahaman et al. (2010); it is designed to eliminate shortcomings in Leasys. The authors have continued to look for ways to improve the capacity and efficiency of the Leasys system in their quest to make identification of plants easier.

\section{Materials and methods}

\subsection{Study materials}

Leaves in 200 savanna tree species in Nigeria were categorized into two major groups based on simple and compound leaves. Numerous other morphological features of the species on stems, flowers, fruits along with photographs of leaves of these 200 species were pre-loaded into the computer system as database for the identification process.

\subsection{Computer program}

The computer program used for systematic identification of plants is Leasys 1.1. A specialized algorithm based on the SQL OLEDB search engine with AND operator, professional reporting system, impressive nature GUI's network compatibility and an enhanced interaction level was implemented as a logical relation to achieve the desired results.

\subsection{System requirements}

For Leasys 1.1 to run effectively on a computer system, the following hardware and software requirements must be met:

\subsubsection{Hardware}

i. Window XP

2 GB free hard disc space

512 MB RAM (minimum)

$1 \mathrm{GHz}$ processor

P III

ii. Window Vista

5 GB free hard disc space

1 GB RAM (minimum)

$1.7 \mathrm{GHz}$ processor

Any vista complaint processor

Mouse (most functions or features may not be performable without a mouse)

\subsubsection{Software}

Direct X8.0 or above. All other software requirements would be installed on installation of Leasys.

\section{Results and discussions}

Hitherto plant samples are usually taken to the herbarium where an expert, a Curator (or Plant taxonomist) goes through the time-consuming and cumbersome checking process using taxonomic keys and herbarium specimens. When in the field, on-the-spot identification of species based on such 
field keys as prepared by Hopkins and Stanfield (1966) can equally be time-consuming and laborious. AbdulRahaman et al. (2010) developed a computer-based system for identification of 200 savanna tree species in Nigeria. The computer software was called Leasys, developed to systematically or electronically identify plants (Figure 1). Figure 1 contains snapshots of processes involved in identification of plants. Detailed description is available in AbdulRahaman et al. (2010). This innovation is useful and effective because it reduces cumbersomeness of manual systems of plant identification.

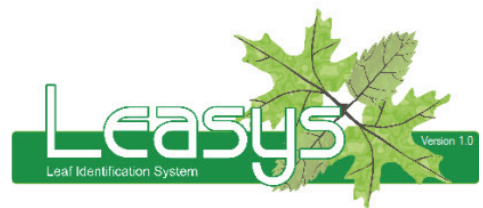

Leasys Splash Screen Banner.

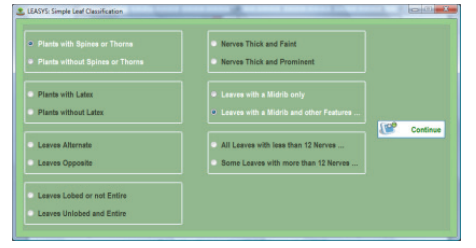

Leasys Property Selection

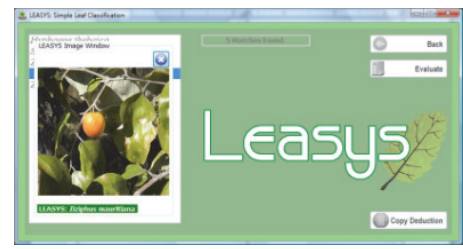

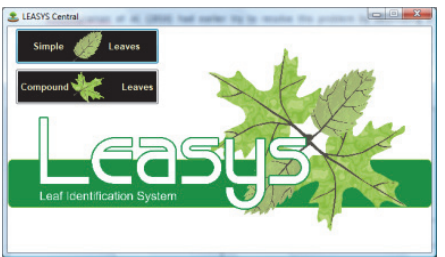

Leasys Path Selection Window

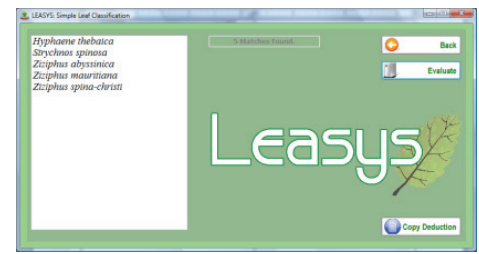

Leasys Deduction Window

\section{Leasys Deduction Window, Generated Results}

Figure 1. Snapshots of processes involved in identification of some savanna plant species in Nigeria using an earlier version of Leasys system (AbdulRahaman et al., 2010)

This paper reports the improvements made on Leasys to get Leasys 1.1. While Leasys which operates only on Deduction Tool, Leasys 1.1 on the other hand has four tools on its main page which allow the user to do at least four main operations. To use Leasys 1.1, user should start with the installed application by activating its icon (Figure 2).

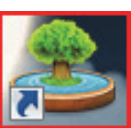

Figure 2. Leasys Icon

The application starts up by loading a splash screen (Figure 3). It is noticeable that during the startup, the application takes a while before coming up. The application first checks the source of all the leaves and all their references.

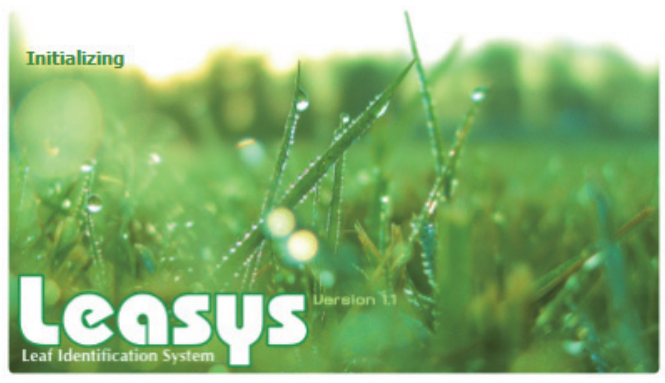

Figure 3. Leasys 1.1 splash screen 
Placing mouse on any of the four tools (Figure 4) will highlight it and display the operations' information. These tools are namely:

1. Leasys Properties Registration

2. Leasys Plant Management

3. Leasys Deduction System

4. Leasys Quick Search

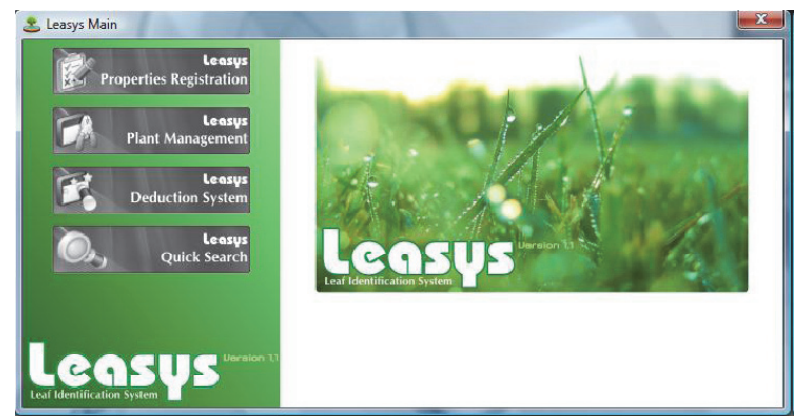

Figure 4. Leasys 1.1 Main

\section{Leasys Property Registration}

This tool area is for the registration of the dichotomous properties in relation to the rules that were used to generate expert system. In this version, Leasys caters for a very important property. It is noticed that a plant can exist in two selection paths in the table that governs Leasys' operations. The previous version of the Leasys had this feature but it could not be controlled. The essence of registration of plant features here is to have an unambiguous way of uniquely creating cells (so to speak) and assign plants into them. Leasys property registration (Figure 5) includes features such as:

Leaf Class: Selection of leaf class or type (simple or compound), that you wish to register. This will then display seven leaf features (for simple leaf option) or eight features (for compound leaf option), each with drop down of two contrasting statements and N/A (not available). You are to select among these seven or eight features of simple or compound leaves respectively.

Clear Button: If there are errors in your selection, clear button will enable you to reset the whole selections.

Save Button: If satisfied with your selections and the program has accepted it, the save button will enable you to save the selected features. The selected features will be checked for valid paths and automatically restructured to ensure accuracy. If the selected path is found previously, the program will tell you.

Print Compendium: This allows you to print generated details. Note that the Leaf Class that you want to print must be selected by right clicking on it for you to do the printing.

Properties of the leaf must be registered before proceeding to the next stage i.e. plant management.

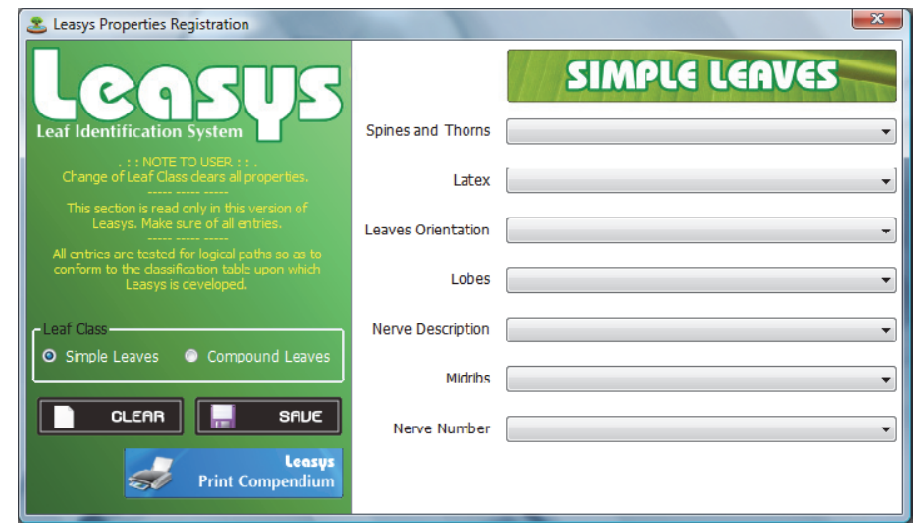

Figure 5. Leasys 1.1 Property Registration 


\section{Leasys Plant Management}

This area is the tool used to insert, update and delete plant data. Leasys Plant Management allows for updating of the database either by adding to or removing from plants already existing in the system. In order words, it is possible to increase the number of plants in the database using this tool. Each plant is checked for duplication as follows: Jointly, no two plants can have same scientific name and property ID under the same class of leaf. The scientific name is used to index the compendium of plants and as such, cannot be edited. In this version of Leasys, the image is only added once and it is as sensitive as the scientific name. Therefore, to change the scientific name or the image, you will need to delete the plant and re-insert it into the system.

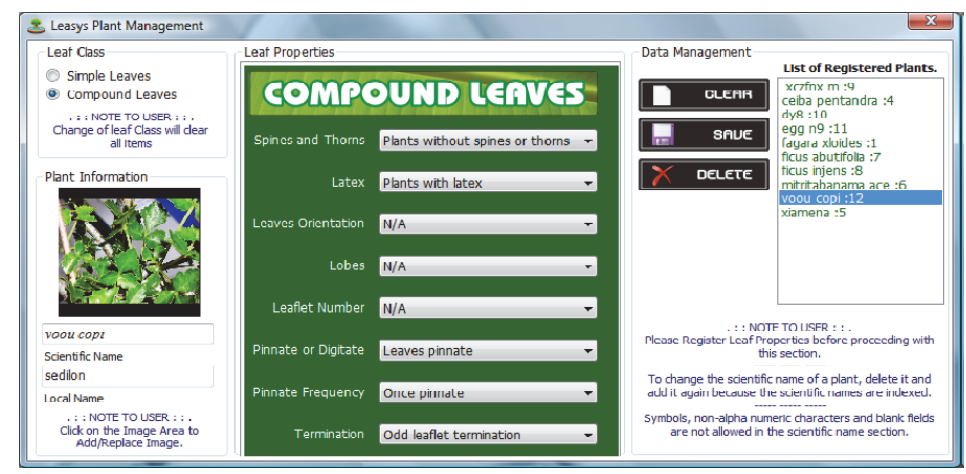

Figure 6. Leasys 1.1 Plant Management

After registration at the Leasys Plant Registration page (Figure 6), the scientific name of the plant appears on the right side on the Leasys plant management page (Figure 7).

\begin{tabular}{|l|}
\hline \multicolumn{1}{|c|}{ List of Registered Plants. } \\
\hline Acacia albida : 9 \\
\hline Acacia dudgeoni $: 10$ \\
Acacia gourmaensis $: 11$ \\
Acacia hebedadoides $: 12$ \\
Acacia hockii $: 13$
\end{tabular}

Figure 7. Leasys 1.1 Plant Management.

It also carries the plant ID thus multiple entries could be identified. Clicking on each scientific name will load the plant information for viewing and management.

In the Leasys plant management page (Figure 6), the following operations are possible using the following tools:

Leaf Class: This enables user to choose between simple and compound leaves. A plant must exist as either a simple or compound leaf. Whichever type is chosen, the program shows the name of the class over the area where the properties are to be selected.

Clear Button: This button enables you to reset all properties. For instance if a plant is focusing and you wish to focus on another plant you can click on the clear button to remove the current plant, in order for you to click on another plant.

Save Button: This button enables you to save an update in plant database.

Delete Button: This is used to delete a selected plant database.

For the interaction of the user, a hidden control is on the picture area that will enable you to view the image larger. Image generated could be enlarged by just right click on the image and subsequently you will see the short cut menu, "View Image Larger" (Figure 8). Clicking on this will open the image in a clearer and larger format.

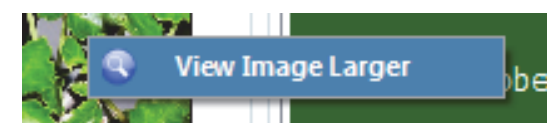

Figure 8. The View Image Larger Command Menu 


\section{Leasys Deduction System}

The main highlight of Leasys 1.1 is captured in Leasys Deduction System (Figure 9). This is the heart of the Leasys program. Using the selected criteria, Leasys will check the entire database for matches and will return a record set in milliseconds (depending on system performance). The record set is tied to the database and has full indexes so that there is no misrepresentation of deductions.

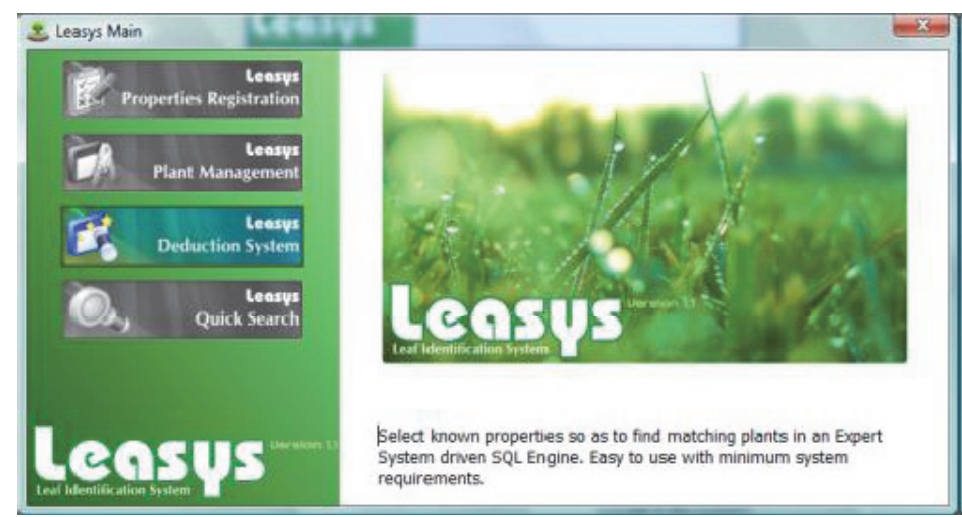

Figure 9. Leasys Deduction System highlighted on Leasys Main page

The deduction system of Leasys is easy to use by just following these steps (Figure 10): STEP 1: Select a Leaf Class (simple or compound);

STEP 2: Select the leaf properties or features pertaining to the plant. Here an unknown plant is traced by selecting features that describe its leaf type among seven or eight features of simple and compound leaves respectively;

STEP 3: Click on deduction button. The button initiates the SQL OLEDB search engine with AND operator as logical relation. If features are correctly selected, deduction button will be clicked to generate list of all plants that are similar to the leaf features input;

STEP 4: Click on an item in the list generated (if the selection is valid).

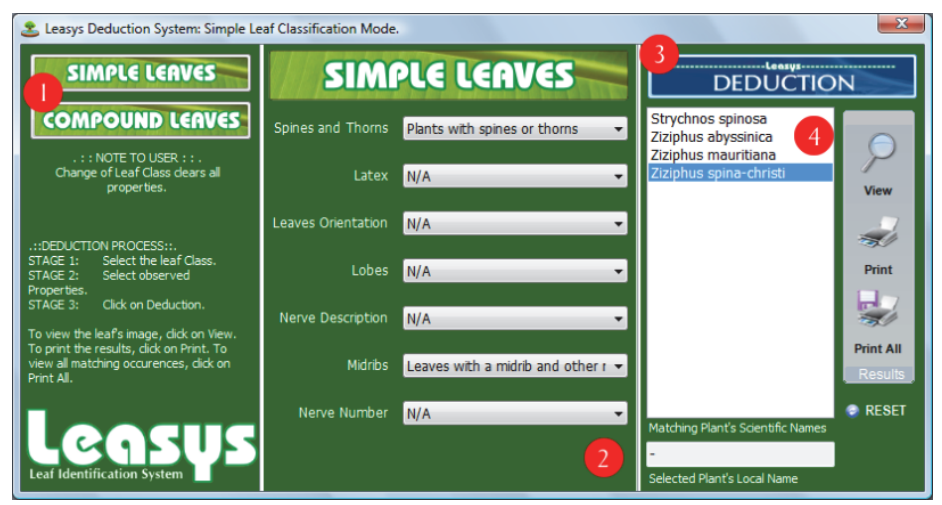

Figure 10. Leasys Deduction System page

From this point, you can click on View (to see the image linked to the Plant), Print (to get a printable version of the plant selected), or Print All (to get a printable version of the deduction set itself).

\section{Leasys Quick Search}

For Leasys to also function as a Directory and not only as a Deduction tool, this module was created to enable the user to search for plants by scientific name, even in cases where the scientific name of such a plant may not be certain (Figure 11). 


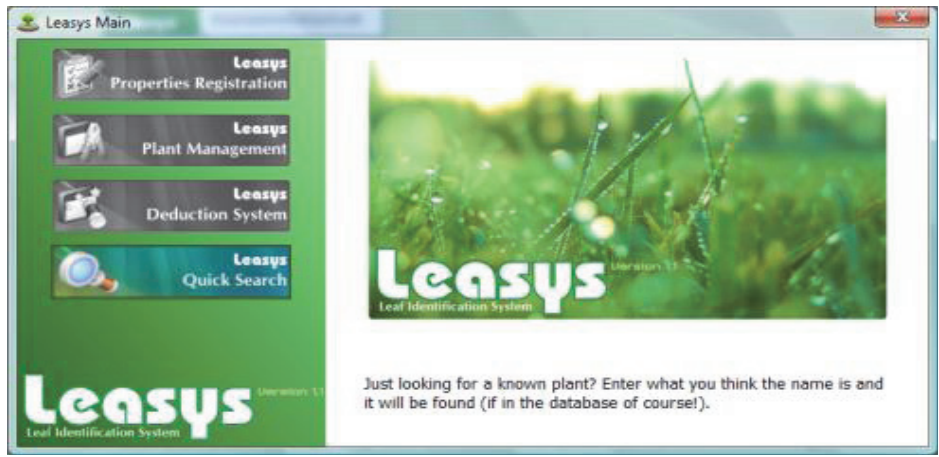

Figure 11. Leasys quick search highlighted on Leasys main page

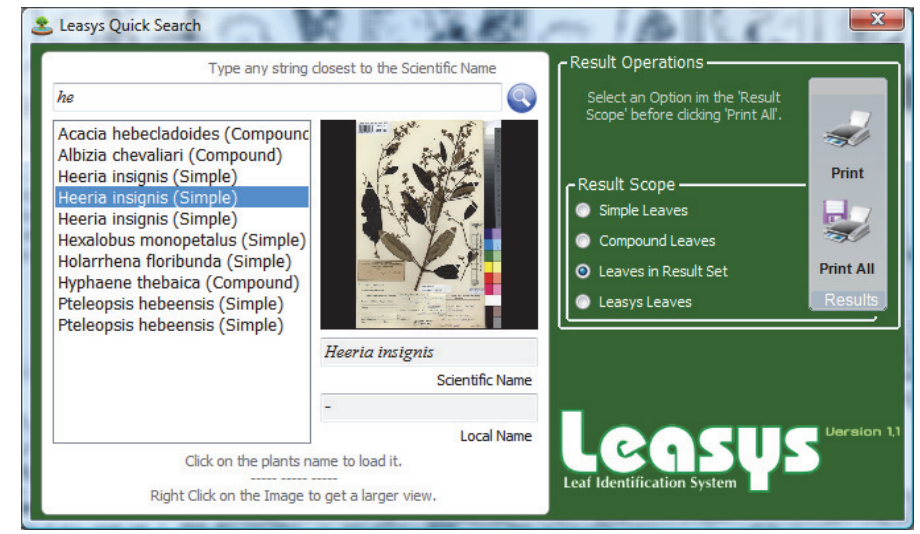

Figure 12. Leasys Quick Search

Following the normal left to right direction, one can start by entering the supposed scientific name in the text area. Leasys automatically searches the database and retrieve the results as shown in Figure 12. The right hand part of the module displays two operations namely the Print button which allow you to prints the details of the currently selected plant, but the Print All button prints the selected result Scope.

Leasys 1.1 makes the process of plant identification easier and faster than using dichotomous keys in Floras and Field keys (Keay and Onochie, 1964; Hopkins and Stanfield, 1966; Hutchinson and Dalziel, 1954, 1958, 1963, 1968, 1972; Ghazanfar, 1989). For example, the classification of the genus Mapania in Hutchinson and Dalziel (1958) goes thus:

1a. Inflorescence on an axillary peduncle which bears reduced leaves only, and subtended by

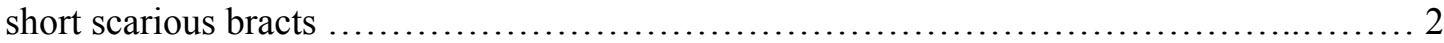

2a. Leaf-blade oblong, $40-85 \mathrm{~mm}$. broad, suddenly narrowed into a pseudopetiole below, obtuse and cuspidate above; sheath inflated, red-purple within ... baldwinii

2b. Leaf-blade linear, $10-45 \mathrm{~mm}$. broad, gradually narrowed below, acute to acuminate;

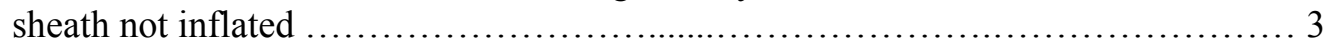

3a. Stigmas 2; leaf-tip asymmetrical, acute; inflorescence straw-coloured, spike more or less confluent ........................................ Linderi

3b. Stigma 3; leaf-tip symmetrical, acuminate; inflorescence brown, spikes discrete, acute, in heads up to $2 \mathrm{~cm}$ across ....................... mangenotiana

1b. Inflorescence on a terminal peduncle bearing normal leaves below, and subtended by leafy bracts .............................................................................. 4

4a. Triangular pseudopetiole present

amplivaginata

Also to identify Parkia biglobosa using indented dichotomous key in the Flora of West Tropical Africa (Hutchinson and Dalziel, 1958), one would need to measure the length of corolla lobes, length fruit, width of fruit, number of pinnae, length and width of pinna and check the pinna pubescence. Whereas this exercise take several minutes, with Leasys 1.1, the exercise of scanning through characters and giving the identity of species takes just a few seconds. 
1a. Corolla lobes very short; leaf-rachis greyish-puberulous; leaflets alternate or subopposite, or opposite towards the apices of pinnae; fruits $19-30 \mathrm{~cm}$. long, $1.5-2.3 \mathrm{~cm}$. broad, not or only slightly indented between the seeds; trees of the savannah regions ................................................................................ 2

2a. Leaflets $36-65$ on each side of the rachis of each pinna, the median ones about 10 (12) $\mathrm{mm}$. long and $2(-3) \mathrm{mm}$. broad; pinnae $8-16$ on each side of the leaf-rachis biglobosa

2b. Leaflets $14-30$ on each side of the rachis of each pinna, the median ones about (11-) $12-18(-20) \mathrm{mm}$. long, (2.5-) $3-5(-6.5) \mathrm{mm}$. broad; pinnae $6-11$ on each side of the leaf-rachis clappertoniana

1b. Corolla lobes long; leaf-rachis rusty-puberulous or tomentellous; forest tree ................... 3

3a. Leaflets $20-55$ on each side of the rachis of each pinna, opposite, the median ones $4.5-10.5(-12.5) \mathrm{mm}$. long, $1-2(-3) \mathrm{mm}$. broad; pinnae $10-26$ pairs; fruits $25-$ $40 \mathrm{~cm}$. long, $1.8-3 \mathrm{~cm}$. broad, markedly indented between the seeds

3b. Leaflets $12-28$ on each side of the rachis of each pinna, opposite to alternate, the median ones $12-38 \mathrm{~mm}$. long, $4-14 \mathrm{~mm}$. broad; pinnae $5-11$ pairs; fruit variable filicoidea

The above indented dichotomous taxonomic keys are very long processes to finally accomplish the identification of a target plant, and it could be time consuming and cumbersome. These and some other challenges of the taxonomic keys are what the Leasys is addressing in solving and making plant identification easier and faster. Similar works are also available on the use of computer for identification of plants (Bao et al., 2007; Zheng et al., 2008; Hossain and Amin, 2010; Rashad et al., 2011; Shabanzade et al., 2011). The main objectives of these computer-based plant identification works are to enhance the processes of identifying an unknown plant with aid of a computer system and to ease the inconveniences for botanists and other scientists in identifying plants.

The Leasys program will, therefore, continue to be upgraded to accommodate more plants species and taxonomic characters to increase its database to cater for study of biodiversity. Moreover, the simplicity and effectiveness of Leasys is in constant review so as to provide a modern application for identification of species.

\section{References}

AbdulRahaman, A.A., L.B. Asaju, M.O. Arigbede and F.A. Oladele, 2010. Computerized system for identification of some savanna plant species in Nigeria. J. Horticul. For., 2: 112-116. http://www.academicjournals.org/jhf/PDF/pdf2010/Jul/Abdulrahaman\%20et\%20al.pdf

Bao, F. S., Xu, E. Y., Wang, Y-X., Chan, Y-F. and Xiang, Q-L. 2007. A leaf recognition algorithm for plant classification using probabilistic neural network. International Symposium on Signal Processing and Information Technology, IEEE, Giza. pp. 11 - 16.

Belhumeur, P.N., W.J. Kress, H. Ling, I. Lopez and R. Ramamoorthi $<\mathrm{I}>$ et al $</ \mathrm{I}>$., 2008. Searching the Worlds Herbaria: A System for Visual Identification of Plant Spicies. Columbia University, New York NY

Breen, P., 2009. Plant identification: Examining leaves. Landscape plants: Image, identification and information. Oregon State University. http://oregonstate.edu/dept/plant\%20ID-Leaves.htm

Cope, E.A., 2001. Muenschers Key to Wood Plants: An Expanded Guide to Native and cultivated Species. Cornell University Press, Ithaca, New York, pp: 337.

Doyle, L. and J. Becker, 1975. Information Retrieval and Processing Melville. Publishing Co. Los Angeles, California, pp: 410.

Ghazanfar, S. (1989). Savanna Plants: An Illustrated Guide. Macmillan Publishers, Hong Kong.

Hopkins, B. and D.P. Stanfield, 1966. Savanna Trees of Nigeria: A Field Key. Ibadan University Press, Ibadan, pp: 37. 
Hossain, J. and Amin, M. A. 2010. Leaf shape identification based plant biometrics. 13th Conference on Computer and Information Technology (ICCIT), Dhaka. pp. $458 \quad-463$.

International

Hutchinson, J. and Dalziel, J. M. 1954. Flora of West Tropical Africa. Volume I Part 1. Crown Agent for Oversea Government and Administrations, London.

Hutchinson, J. and Dalziel, J. M. 1958. Flora of West Tropical Africa. Volume I Part 2. Crown Agent for Oversea Government and Administrations, London.

Hutchinson, J. and Dalziel, J. M. 1963. Flora of West Tropical Africa. Volume II. Crown Agent for Oversea Government and Administrations, London.

Hutchinson, J. and Dalziel, J. M. 1968. Flora of West Tropical Africa. Volume III Part 1. Crown Agent for Oversea Government and Administrations, London.

Hutchinson, J. and Dalziel, J. M. 1972. Flora of West Tropical Africa. Volume III Part 2. Crown Agent for Oversea Government and Administrations, London.

Keay, R. W. J. and Onoche, C. F. A. 1964. Nigerian Trees. Federal Department of Forest Research, Ibadan.

Ramesh, B. R. and Ayyappan, N. 2009. Computer aided plant identification system to rejuvenate traditional taxonomy. Department of Ecology, French Institute of Pondicherry.

Rashad, M. Z., el-Desouky, B. S., Khawasik, M. S. 2011. Plants Images Classification Based on Textural Features using Combined Classifier. International Journal of Computer Science and Information Technology, 3(4): $93-100$.

Shabanzade, M., Zahedi, M., Aghvami, S. A. 2011. Combination of local descriptors and global features for leaf recognition. Signal and Image Processing, 2(3): 23 - 31.

Singhal, A., 2001. Modern information retrieval: A brief overview. Bull. IEEE Comput. Soc. Tech. Committee Data Eng., 24: 35 - 43.

Zheng, L., Kong, J. Zeng, X. and Ren, J. 2008. Plant species identification based on neural network. Proceedings of the ICNC Fourth International Conference on Natural Computation, Oct. 18-20, Jinan, pp: 90 - 94. 